\title{
Design and testing of iodine cells for metrological laser application
}

\author{
A.M. Negriyko, O.V. Boyko, N.M. Kachalova, V.M. Khodakovskiy, O.I. Klochko \\ Institute of Physics, NAS of Ukraine, 46 prospect Nauki, 03022 Kyiv, Ukraine \\ Phone: +38(044) 26512 20; fax:+38 (044) 26515 89; e-mail: negriyko@iop.kiev.ua
}

\begin{abstract}
The design and performance of iodine vapor cells for frequency stabilized laser applications are presented. The traditional design of iodine vapor cell and special development of cell for fluorescence applications are studied. The sets of eight iodine cells developed and filled in Institute of Physics NAS Ukraine were tested in the He-Ne/ $/ 27 \mathrm{I}_{2}$ frequency stabilized lasers. The nonlinear resonance width and contrasts for different cells were measured. The beat frequency method was used for study of laser output frequency differencies for lasers stabilization using different cells. The results of iodine cells testing shown that for glass cells prepared more than 8 years ago the resonance width is appr. $2.2 \mathrm{MHz}$ and frequency differencies are in the rather narrow area $\leq 15 \mathrm{kHz}$. The standard uncertainty of the frequency stabilized $\mathrm{He}-\mathrm{Ne} /{ }^{127} \mathrm{I}_{2}$ lasers is $11.7 \mathrm{kHz}$. The tests shown that developed cells meet the demands to applications in metrological lasers.
\end{abstract}

Keywords: laser, metrology, iodine cell, frequency stabilization, laser fluorescence, nonlinear absorption, iodine cell technology.

Paper received 16.05.03; accepted for publication 17.06.03.

\section{Introduction}

According to Recommendation 1 of Comite International des Poids et Mesures (CIPM) the radiations of six laser sources stabilized by the iodine absorption (argon ion laser, second harmonics of Nd:YAG laser and four types of $\mathrm{He}-\mathrm{Ne}$ laser) are recommended as radiations for realization of the meter unit [1]. As sources of standard wavelengths for length metrology, the iodine stabilized HeNe lasers are now the most widely used. The He-Ne laser stabilized by some hyperfine structure component of molecular iodine provides the set of standard wavelengthes:

1. Absorbing molecule ${ }^{127} \mathrm{I}_{2}$, transition $26-0, \mathrm{R}(12)$, component $\mathrm{a}_{9}(\lambda \approx 543 \mathrm{~nm})$ provide adopted value of optical frequency $f_{\mathrm{a} 9}=551579482.96 \mathrm{MHz}$, and vacuum wavelength $\lambda_{\mathrm{a} 9}=543516333.1 \mathrm{fm}$;

2. Absorbing molecule ${ }^{127} \mathrm{I}_{2}$, transition $9-2, \mathrm{R}(47)$, component $\mathrm{a}_{7}(\lambda \approx 612 \mathrm{~nm})$ provide adopted value of optical frequency $f_{\mathrm{a} 7}=489880354.9 \mathrm{MHz}$, and vacuum wavelength $\lambda_{\mathrm{a} 7}=611970770.0 \mathrm{fm}$;

3. Absorbing molecule ${ }^{127} \mathrm{I}_{2}$, transition 11-5, R(127), component $\mathrm{a}_{13}$ or $\mathrm{i}(\lambda \approx 633 \mathrm{~nm})$ provide adopted value of optical frequency $f_{\mathrm{a} 13}=473612214705 \mathrm{kHz}$, and vacuum wavelength $\lambda_{\mathrm{a} 13}=632991398.22 \mathrm{fm}$;
4. Absorbing molecule ${ }^{127} \mathrm{I}_{2}$, transition $8-5, \mathrm{P}(10)$, component $\mathrm{a}_{9}$ or $\mathrm{g}(\lambda \approx 640 \mathrm{~nm})$ provide adopted value of optical frequency $f_{\mathrm{a} 9}=468218332.4 \mathrm{MHz}$, and vacuum wavelength $\lambda_{\mathrm{a} 9}=640283468.7 \mathrm{fm}$.

Additionally, as "other sources" the reference radiation the frequency doubled He-Ne laser stabilized on transition 17-1, $\mathrm{P}(62)$ component $\mathrm{a}_{1}$ or o $(\lambda \approx 576 \mathrm{~nm})$ of molecule ${ }^{127} \mathrm{I}_{2}$ is recommended with optical frequency $f_{\mathrm{a} 1}=520206808.4 \mathrm{MHz}$, and vacuum wavelength $\lambda_{\mathrm{a} 1}=576294760.4 \mathrm{fm}$.

According to [1], the list of absolute frequencies of other transitions related to those adopted as recommended includes the number, namely 28 , of iodine molecular transitions, both ${ }^{127} \mathrm{I}_{2}$ molecules and other iodine molecules $\left({ }^{129} \mathrm{I}_{2},{ }^{127} \mathrm{I}^{129} \mathrm{I}\right)$.

The iodine-stabilized diode lasers are developed now too for metrological applications, too [2].

These data show the high importance of molecular iodine as a quantum system that provides a wide number of reference transitions for metrological applications.

Now the most common way of frequency stabilization of helium-neon laser based on the placing of glass cell filled by iodine vapour inside or outside of laser cavity. The Doppler-free resonances in the laser output are pro- 


\section{A.M. Negriyko et al.: Design and testing of iodine cells for ...}

duced due to saturated absorption of iodine vapour. The laser frequency modulation through the nonlinear absorption resonance was executed, and the signal at the triple frequency of modulation was detected to provide the third derivative of line profile. The electronic servo system keep the laser frequency as close as possible to the zero point of third derivative and provide the laser frequency stabilization to hyperfine iodine component. The precision of laser radiation frequency, in the final analysis, is defined by precision of hyperfine component frequency position.

It is known that the hyperfine frequency is influenced by some effects: amplitude of laser frequency modulation, iodine pressure, laser intracavity power [3], wavefront geometry [4], gas lens effects [5, 6], elastic velocitychanging collisions effect $[7,8]$, contamination of the reference gas [9], etc. Among of main factors defining the net error budget of stabilized laser frequency are uncertainties connected with iodine absorption cell: iodine purity uncertainty $-5 \mathrm{kHz}$, cold-finger temperature $2.5 \mathrm{kHz}$. The laser frequency reproducibility level of some parts in $10^{10}$ needs the precise control and keeping laser and iodine cell parameters stable. The recommended values of iodine pressure (defined by cold finger temperature), temperature of iodine cell walls, intracavity laser power, modulation amplitude and beam geometry, the adequate accuracy of this parameters [1] are based on the many-year investigations of all manifold of laser parameters impact on the laser frequency stability and reproducibility.

\section{Iodine cell design and preparation}

The iodine cells were of subject of a number investigations [9-16]. The international comparision of iodine absorption cells $[3,12,14]$ conforms that observed frequency shifts of the hyperfine components in iodine are strongly linked to impurities in the iodine cells. Therefore, the development of improved iodine cell preparation technologies and accurate cell testing is rather important for advanced metrology lasers.

We present the iodine cells for metrological laser applications designed in two versions: the iodine cell Type I meeting the demands of Recommendation of Comite International des Poids et Mesures (CIPM ) and experimental iodine cell Type II for both nonlinear absorption and nonlinear fluorescence applications. The Type I glass cell (Fig. 1) is $6.5 \mathrm{~cm}$ length and inner tube diameter $5 \mathrm{~mm}$. The Brewster glass windows are sealed to glass tube by glass cement. The cell has the side glass finger for iodine pressure control.

The type II cell (Fig. 2) was glass-ceramic (zerodure) made and has two quartz Brewster windows and side window for fluorescence light detection. The additional enhancement of fluorescence signal is achieved by using the builted-in into cell body light integrated sphere. The integrated sphere is made from milk glass and has the opened round hole oriented to the side window output.

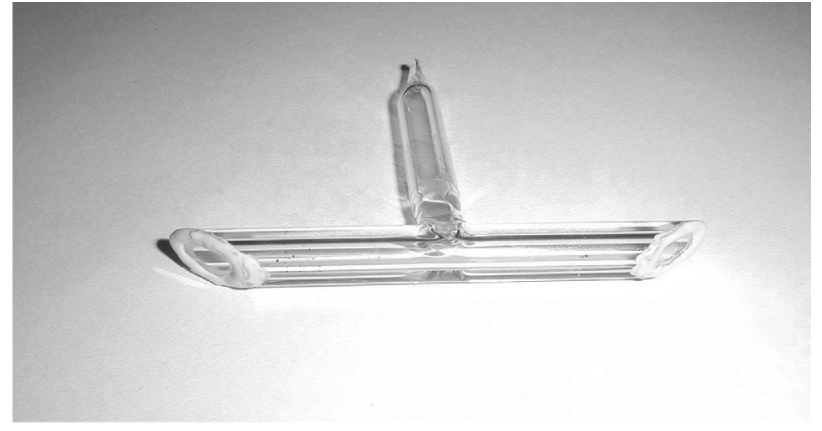

Fig. 1. The Type I iodine glass cell.

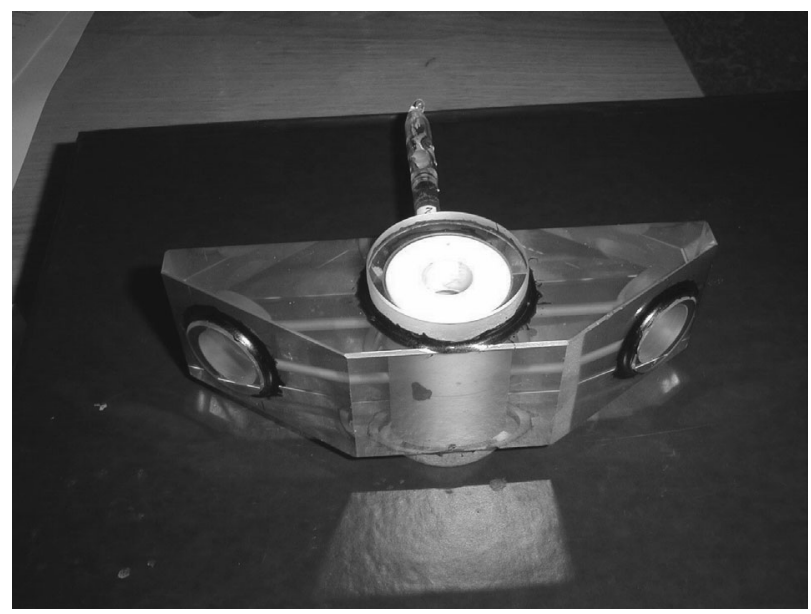

Fig. 2. The Type II iodine glass-ceramic cell.

The glass-made side arm is attached to the cell body by special junction. The junction is made from set of glass rings with matched temperature expansion indexes to prevent its destruction during thermocycling treatments. The Brewster windows are sealed to the glass-ceramic cell body by a deep optical contact using additional fastening by epoxide resin.

The most important parameter of the used iodine cell is adequate purity of the iodine and absence of foreign gases within the sealed absorption cell. Due to possible leakage or/and outgassing some foreign gas can be added to the original iodine filling. The cell filling procedure used in Laser spectroscopy Laboratory in Institute of Physics (National Academy of Sciences of Ukraine) includes several stages: 1. Iodine distillation. 2. Iodine cells evacuation. 3. Iodine cells outgassing. 4. Filling iodine cells by iodine. 5 . Cutting the filled cell from vacuum system.

The set-up for iodine cells filling is shown in Fig. 3. The crystalline iodine was placed into glass ampoule arranged by special output tube for attachement to the vacuum pipeline without breaking the high-vacuum conditions. The ampoule filled by iodine was sealed to the vacuum pump recieving tube and was evacuated to the pressure less than $10^{-6}$ Torr. After evacuation the ampoule was cut from vacuum pipeline and was sealed by 


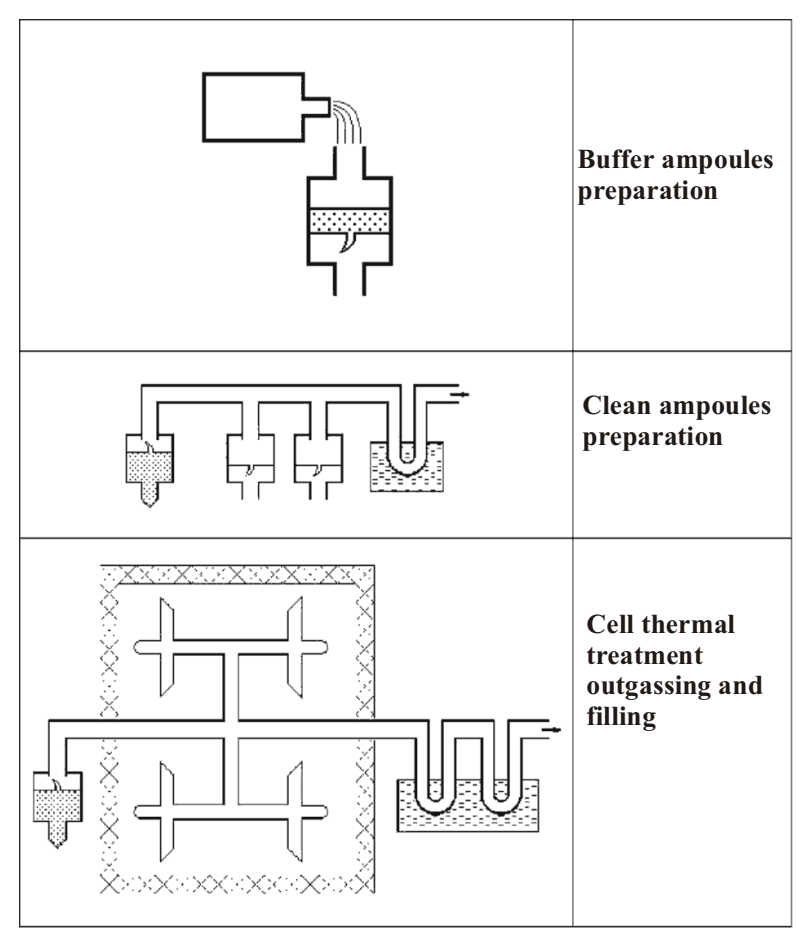

Fig. 3. The iodine cell filling setup.

opposite side arranged by abovementioned special output tube to the high vacuum system. After lowering pressure to the level less than $10^{-6}$ Torr the glass divide wall was removed and the ampoule was connected to the high vacuum line. During this preliminare operations ampoule was cooled by liquid nitrogen to prevent the iodine leakage. After finishing this preliminary preparation, the liquid nitrogen was removed from iodine contained ampoule and was tranferred to the empty ampoules having similar design. The crystalline iodine was sublimated and moved to cooled ampoules: the distillation of iodine was realized. After sublimation approximately $3 / 4$ of iodine, the clear ampoules with iodine were cutted from vacuum pipeline and used at the next stages of iodine cell filling.

The iodine cell filling was made using the vacuum system equipped by U-shape protection traps cooled by liquid nitrogen to prevent the cell pollution by vacuum oil vapors and arranged by oven for cells thermal treatment. The thermal processing includes computer controllable heating of cells up to the temperature $350^{\circ} \mathrm{C}$. To prevent the possible influence of temperature gradients onto the vacuum joints caused by minute mismatch in thermal expansion indexes of diffrent cell parts, the heating system was able to provide the heating with controllable rate up to $0.2^{\circ} \mathrm{C} / \mathrm{min}$. The empty cells (usually four) were sealed to the glass vacuum pipeline. The ampoule with distillated iodine was sealed to common vacuum pipeline, but the iodine contained volume was separated from vacuum pipeline by breaking glass wall. The vacuum pipeline and empty cells were evacuated to the pressure $10^{-6}$ Torr and heated to the $300^{\circ} \mathrm{C}$ with continuous evacuation. After finishing the thermal treatment and cooling the cells to the room temperature, the glass wall separating iodine from vacuum system was removed. The liquid nitrogen was used for cell cooling and deposition of crystalline iodine into the cells. The filled with iodine cell was cut off from the vacuum pipeline by acetylene torch. All the process of cell vacuum and thermal treatment needs appr. 60 hours.

\section{The iodine cells tests}

The hyperfine components of molecular iodine are shifted and widened by the presence of foreign atoms and molecules $[9,10]$.

The direct measurement of frequencies difference of two lasers with reference and tested iodine cells placed in turn into each laser were chosen for the cell comparison.

The experimental laser setup is shown in Fig. 4. The laser cavity is formed by rear mirror $3 \mathrm{a}$ mounted at piezoelectric transducer 4 (PT) and output mirror $3 \mathrm{~b}$. The mirror mounts are spaced by three invar alloy rods 8 . The rf-pumped He-Ne laser tube 1 (LT) and iodine absorption cell 2 are placed into the cavity. All laser elements are mounted on the massive steel table placed on the concrete base and are insulated from acoustic noises by sound-absorbing protector. The iodine pressure is controlled by cell sidefinger temperature regulated by Peltier cooler. The temperature control and stabilization system allows to set the temperature from $0^{\circ} \mathrm{C}$ to room temperature with precision $0.01{ }^{\circ} \mathrm{C}$. Detailed description of experimental set up was given [7].

The frequency modulation voltage and error signals from frequency locking servo system are applied to PT. By modulating the laser frequency through the saturated absoption resonance of iodine, a signal at three times the modulation frequency is detected to give a third derivative line profile. This signal is used for laser frequency stabilization onto a iodine hyperfine component by electronic servo system. The laser frequency is modulated by

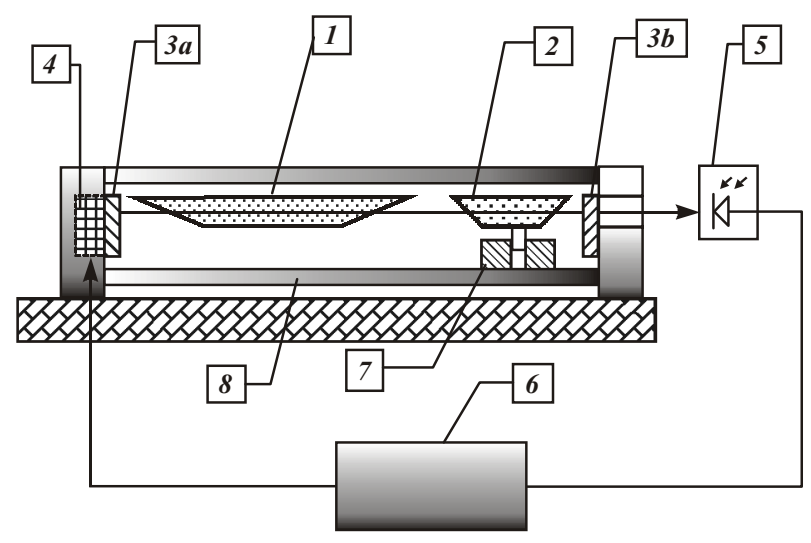

Fig. 4. The experimental laser setup: 1 - laser tube; 2 - iodine cell; 3 - laser mirrors; 4 - piezoelectric transducer; 5 - photodetector; 6 - frequency locking servo system; 7 - Peltier cooler; 8 - laser cavity rods. 


\section{A.M. Negriyko et al.: Design and testing of iodine cells for ...}

the sine voltage, which is applied to PZT. The servosystem stabilizes the mean frequency of the laser by locking on the saturated absorption components $a, b, c, d, e, f, g, h$, $i$ and $j$ of the HFS components of the R(127) absorption line of the 11-5 vibration band of the $\mathrm{B}^{3} \Pi_{\mathrm{u}}{ }^{+} \leftarrow \mathrm{X}^{1} \Sigma_{\mathrm{g}}{ }^{+}$transition of the ${ }^{127} \mathrm{I}_{2}$ molecule.

When the saturation of absorption is weak, the output power curve of the laser can be expressed as [19]:

$P(v)=P_{0} \exp \left\{-\left(\frac{v-v_{g}}{\Delta v_{D}}\right)^{2}\right\}\left[1+\Sigma k_{i} \frac{1}{1+\left(\Delta v_{i} / \Gamma_{i}\right)^{2}}\right]$,

where $v_{g}$ is the central frequency of the Doppler-broadened gain profile, $\Gamma_{i}$ is the homogeneous width and $k_{i}$ is the contrast of $i$-resonance.

The frequency shift $\Delta \Omega$ is defined as the detuning $\Delta v$ corresponding to the third harmonic $\mathrm{S}_{3}$ zero

$S_{3}(\Delta \Omega)=0$,

where

$S_{3}(\Delta v)=\frac{f}{2 \pi} \int_{0}^{2 \pi / f} P\left(\Delta v+\frac{D}{2} \cos (f t)\right) \cos (3 f t) d t$.

where $D$ is the frequency deviation, $f$ is the modulation frequency, $P(v)$ is the output power.

To obtain the parameters of the resonances, we performed a least-square fit of the experimental dependencies of the third harmonic signals on the laser frequency to the theoretical ones given by expressions (4) and (5). The change of the laser frequency was measured by detecting a beat frequency between the laser under investigation and the reference laser. The reference laser was stabilized to the HFS component $\mathrm{f}$ of the line R(127) 115 of $\mathrm{B}^{3} \Pi_{\mathrm{u}}{ }^{+} \leftarrow \mathrm{X}^{1} \Sigma_{\mathrm{g}}{ }^{+}$transition of ${ }^{127} \mathrm{I}_{2}$ molecule.

When comparing the stabilized lasers, the matrix measurement method [20] is usually used for obtaining the frequency difference between lasers. The method is based on the measurements of beat-frequencies between lasers stabilized by different HFS components $d, e, f$, and $g$ excluding stabilization by the equal components. The beatfrequencies are the matrix items. Processing the matrix gives us the frequency differences between lasers.

The beat frequency measurements were made using the experimental set up depicted in Fig. 5. The signal of beating was formed as a heterodyne signal produced by two laser beams from reference and tested lasers. Both laser beams were superimposed at the avalanche photodiode (APD) and its output with frequency equals to beat frequency of tested and reference lasers was directed to the frequency meter and spectrum analyzer and processed by computer.

Eight iodine cells were selected for testing. The glass cells No.1, 6-10 (Fig. 1) were produced by Kharkov State

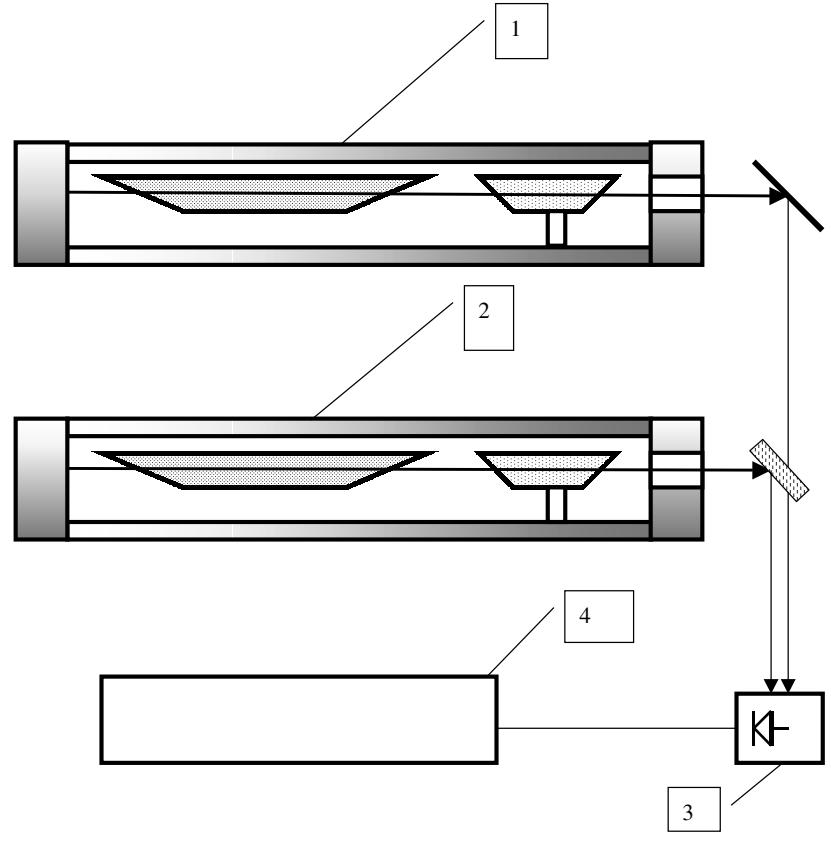

Fig. 5. The beat frequency measurements setup: 1 - reference laser; 2 - laser with tested cell; 3 - avalanche photodiode; 4 frequency counter.

Scientific Research Institute of Metrology and iodine filled by Laser spectroscopy Laboratory Institute of Physics NAS Ukraine. The cell length was $6.5 \mathrm{~cm}$ and Brewster windows were sealed by glass cement. All cells were filled by iodine in 1994.

The Zerodure cells No. 2, 45 (Fig. 2) with optical path length $11.0 \mathrm{~cm}$ were produced by CDO "Arsenal" (Kiev) as experimental cells for both iodine saturated absorption and saturated fluorescence investigations. These cells were filled by iodine in October, 1998.

Two identical helium-neon lasers were used for cell testing. First laser serves as a reference laser. The iodine cell No.3 (similar to cells 1, 6-10) was used as a reference cell and was placed into the first laser cavity. During all testing process the only this cell was used as reference one and rest of laser parameters were keeping stable. The rest cells were placed in turn into the second laser cavity. The sidearms temperature during measurements was kept at $15.00 \pm 0.01{ }^{\circ} \mathrm{C}$, cell wall temperature was $22^{\circ} \mathrm{C}$. The frequency modulation width, peak-to-peak of both lasers was $D=6.0 \pm 0.1 \mathrm{MHz}$.

To make the cell quality estimation, the third derivative signals of the hyperfine components were studied. The examples of results are shown in Fig. 6,7 for the cells No.5, 6, respectively.

The resonances width and contrasts, calculated by least square technique (see detailes in [18]) are shown in Figs 8 and 9, respectively. The halfwidth of resonance for cells No. 1, 6-10 is $2.2 \mathrm{MHz}$. The contrasts for cell No. $6-10$ are $0.03-0.07 \%$. The contrast $0.1 \%$ for cell No. 1 is caused by lower saturating laser intensity. The output power of the experimental laser was determined by cell optical quality and shown in Fig. 10. 
A.M. Negriyko et al.: Design and testing of iodine cells for ...
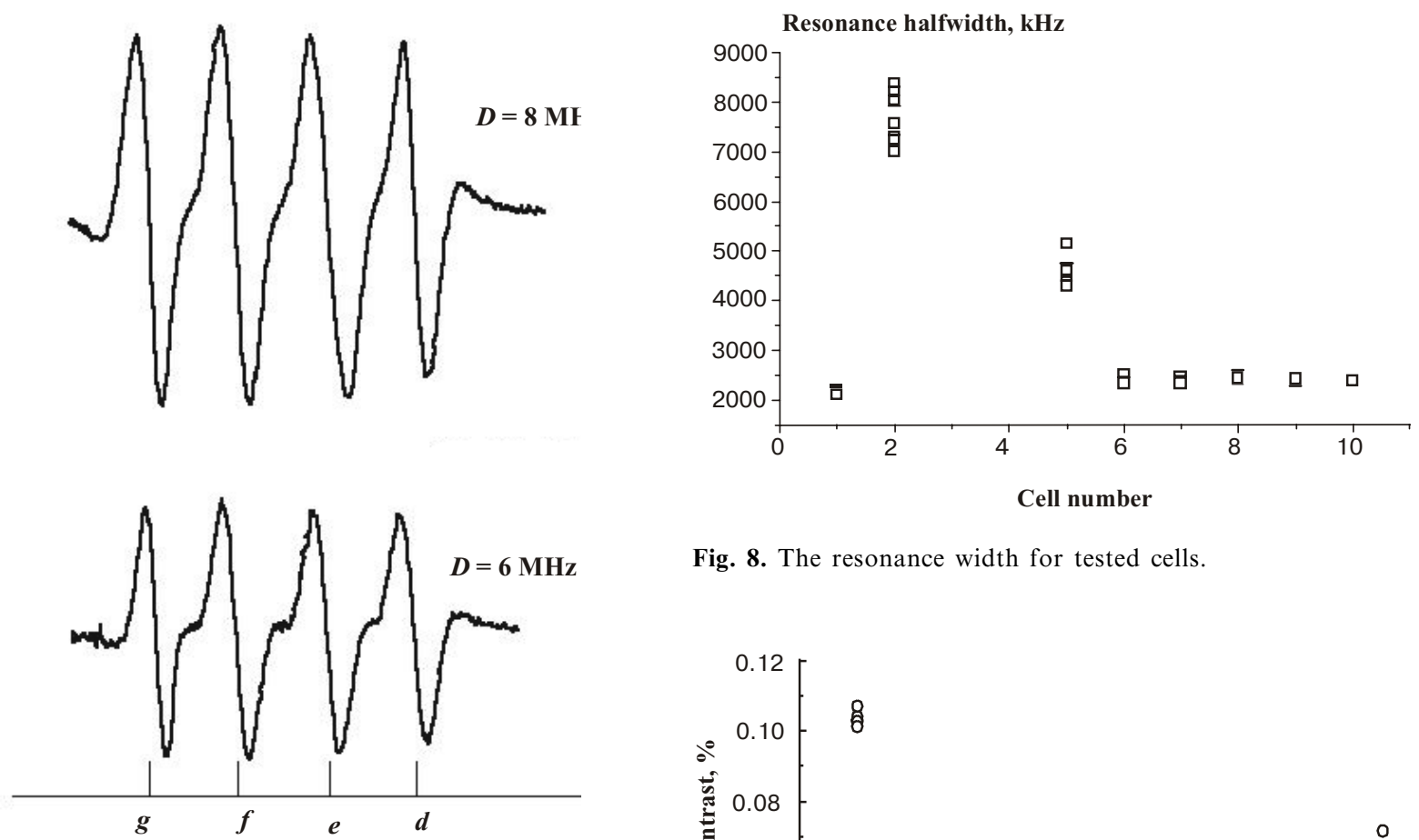

Fig. 8. The resonance width for tested cells.

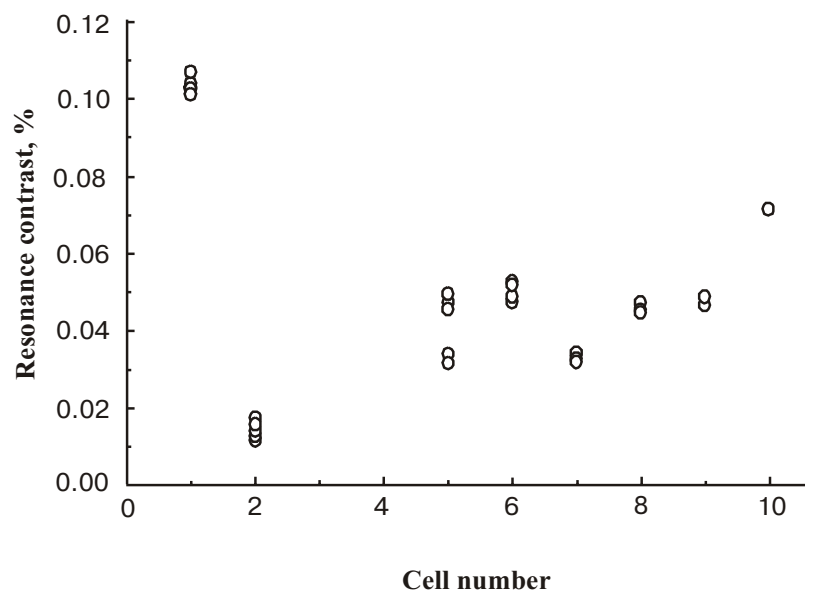

Fig. 9. The resonance contrasts for tested cells.

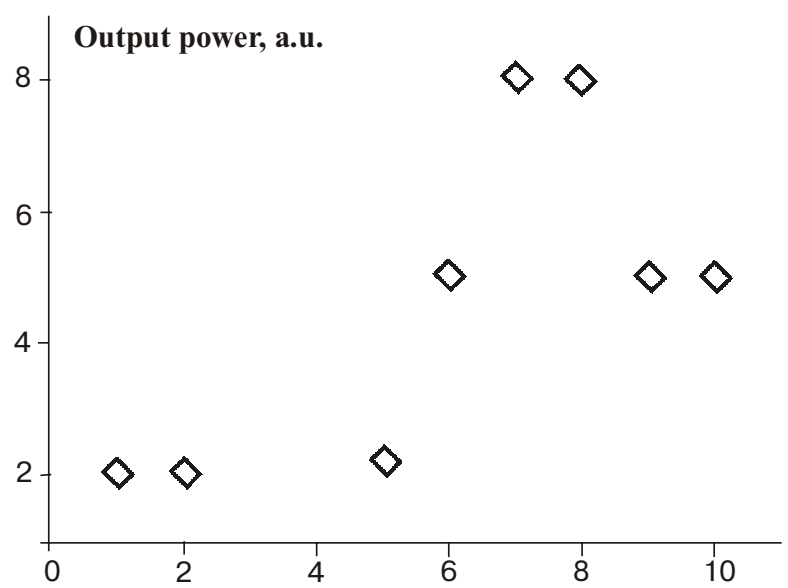

Fig. 7. The third derivative signal of the hyperfine components for the glass cell.

The resonances for cells No. 2 and 5 have much worse parameters, probably due to the presence of foreign gases in the cells.

The beat frequency of reference and experimental lasers was analyzed using the well known Bayer-Helms

Fig. 10. The output power of laser with tested cell inside the cavity.

matrix method of frequency differences for $d, e, f, g$ hyperfine components (see details in [17]). The results of measurements are presented in Fig. 11. The beat frequency measurements show that frequency shifts for cells No. $6-10$ are fitted in the rather narrow area $\leq 15 \mathrm{kHz}$. 
A.M. Negriyko et al.: Design and testing of iodine cells for ...

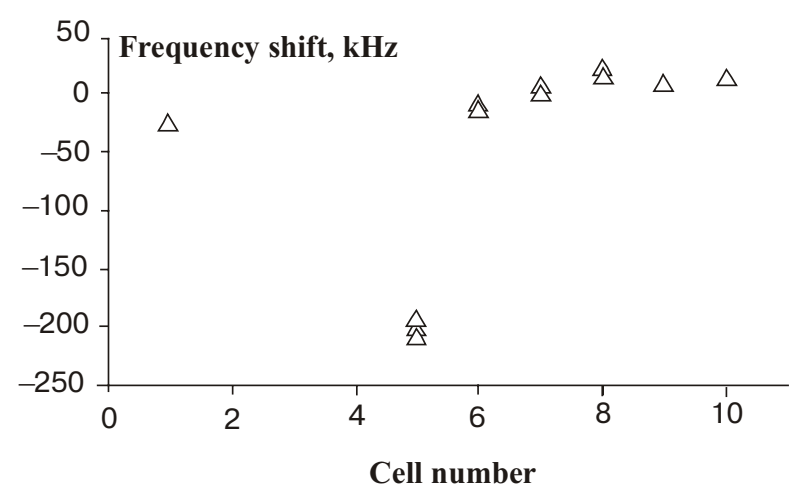

Fig. 11. The frequency shifts for tested cells.

The cell No. 1 has the shift $\approx 29 \mathrm{kHz}$ at laser output power approximately twice lower comparing to output for cells No. 6-10. These observed shift magnitudes confirm the high quality of developed iodine cells. The cell design provides the long lifetime of cells (more than 8 years).

The standard uncertainty of the frequency of stabilized $\mathrm{He}-\mathrm{Ne} /{ }^{127} \mathrm{I}_{2}$ lasers is $11.7 \mathrm{kHz}$.

The previous results on the comparisions of Institute Physics He-Ne laser stabilized on the iodine hyperfine transitions and laser of Ukrainian State Length Standard of Kharkiv Metrology Institute [17] demonstrated the frequency shifts of the same order of magnitude.

\section{Laser fluorescence test of iodine cell for iodine-129 contamination}

The uncontrolled ${ }^{129}$ I contamination of iodine cell used for laser frequency stabilization is a possible source of additional errors in stabilized laser frequency reproducibility [12]. The impact of uncontrolled ${ }^{129}$ I contamination in uncertainty budget is comparable with impact of the rest known factors at the ${ }^{129}$ I contamination level as small as $0.25 \%$ of ${ }^{127} \mathrm{I}_{2}$ concentration [21]. To exclude the influence of ${ }^{129}$ I contamination, we use the additional iodine cell test based on the laser fluorescence technique [22].

Laser fluorescence is high sensitive technique for detection of small amounts of atoms and molecules. The application of laser fluorescence to detection of minute iodine impurities was demonstrated more than twenty years ago [23]. The iodine density in the range $5 \cdot\left(10^{8}-10^{13}\right) \mathrm{cm}^{-3}$ was measured using dye laser excited fluorescence. In [22], we demonstrated the laser fluorescence technique application to the heteroisotope iodine molecules detection.

The detection of small amounts of foreign iodine isotopes is based on selective excitation of heteroisotope molecules. At the relative concentration of foreign iodine atoms $\alpha=n_{1} / n_{0}$, where $n_{1}-$ number of ${ }^{129}$ I atoms and $n_{0}-$ number of all iodine atoms, the relative concentrations of ${ }^{127} \mathrm{I}_{2}$ molecules $\mathrm{N}_{1},{ }^{129} \mathrm{I}^{127} \mathrm{I}$ molecules $\mathrm{N}_{2}$ and ${ }^{129} \mathrm{I}_{2}$ molecules $\mathrm{N}_{3}$ are $\mathrm{N}_{1}: \mathrm{N}_{2}: \mathrm{N}_{3}=\left(1-\alpha^{2}\right): 2 \alpha(1-\alpha): \alpha^{2}$. In the case of a relatively low contamination level $(\alpha<<1)$ the foreign iodine isotope ${ }^{129} \mathrm{I}$ presents in the cell mainly as heteroisotope ${ }^{129} \mathrm{I}^{127} \mathrm{I}$ molecules: e.g., for $\alpha=0.01(1 \%)$ the iodine gas in cell contains $98 \%$ of ${ }^{127} \mathrm{I}_{2}$ molecules and approximately $2 \%$ of ${ }^{129} \mathrm{I}^{127} \mathrm{I}$ molecules. The relative concentration of ${ }^{129} \mathrm{I}_{2}(0.01 \%)$ is negligibly small. This is a reason to consider the iodine cell as filled by two kinds of molecules: homoisotope diatomic iodine molecules ${ }^{127} \mathbf{I}_{2}$ and heteroisotope ${ }^{129} \mathrm{I}^{127} \mathrm{I}$ molecules.

We compare absorption spectra of ${ }^{127} \mathrm{I}_{2}$ and heteroisotope ${ }^{129} \mathrm{I}^{127} \mathrm{I}$ molecules and select several "windows" in ${ }^{127} \mathrm{I}_{2}$ spectra where rather strong ${ }^{129} \mathrm{I}^{127} \mathrm{I}$ absorption lines are presented. These lines were selected as sensitive ones for detection of iodine-129 in the cell. As figure of merit $Q$ for reference lines, we use the absorption factors ratio for ${ }^{129} \mathrm{I}^{127} \mathrm{I}$ and ${ }^{127} \mathrm{I}_{2}$ molecules at the tuning to the ${ }^{129} \mathrm{I}^{127} \mathrm{I}$ absorption line center:

$$
Q=I_{(127,129)} \sqrt{\pi}\left(\sum \frac{\left.I_{(127,129)}\right) k u}{\left(\omega-\omega_{0(127,129)}\right)^{2}+\gamma^{2}}\right)^{-1}
$$

where summation is realized by all the frequencies $\omega_{0(127,127)}$ corresponding to ${ }^{127} \mathrm{I}_{2}$ molecule absorption lines. It was shown [22] that in the tuning range of Rhodamine $6 \mathrm{G}$ dye laser more than 10 lines with $Q \geq 2 \cdot 10^{5}$ are placed. The positions of spectral lines in the spectral region near ${ }^{129} \mathrm{I}^{127} \mathrm{I}$ absorption line $2 \rightarrow 12 \mathrm{P}(82)(\lambda=601.978 \mathrm{~nm}$ in air) with high $Q=2.9 \cdot 10^{5}$ were calculated. With proper selection of reference ${ }^{129} \mathrm{I}^{127} \mathrm{I}$ absorption line, the fluorescence intensity of ${ }^{129} \mathrm{I}^{127} \mathrm{I}$ molecules has the same order of magnitude as ${ }^{127} \mathrm{I}_{2}$ molecules fluorescence intensity at the level of ${ }^{129}$ I concentration as small as $10^{-5}$ of ${ }^{127}$ I concentration.

Using this technique (see experimental setup at Fig. 12), we provide the laser fluorescence test of prepared iodine cells for the ${ }^{129}$ I pollution with sensitivity not worse than $0.03 \%$ of ${ }^{127} \mathrm{I}_{2}$ concentration. At this contamination level, the iodine hyperfine structure shifts caused by ${ }^{129}$ I presence are negligibly small.

\section{Conclusions}

The technology of iodine cell filling used in the Institute of Physics, NAS of Ukraine, is described. The iodine cell test results are presented. The iodine cells prepared in accord to developed technology demonstrate the ten-year lifetime (glass cells). The glass-ceramic cells have more short lifetime, probably due to more developed internal surface with more intensive outgassing.

The standard uncertainty of the frequency stabilized $\mathrm{He}-\mathrm{Ne} /{ }^{127} \mathrm{I}_{2}$ lasers calculated on the results of laser frequency stabilization using a number of glass iodine cells is $11.7 \mathrm{kHz}$.

The work was done with partial financial support of INTAS grant \# INTAS 99-1B- 00019, Ministry of Education and Science of Ukraine grant \# 8/87-2001 and NAS Ukraine grants \# B72 and ВЦ98/24. 
A.M. Negriyko et al.: Design and testing of iodine cells for ...

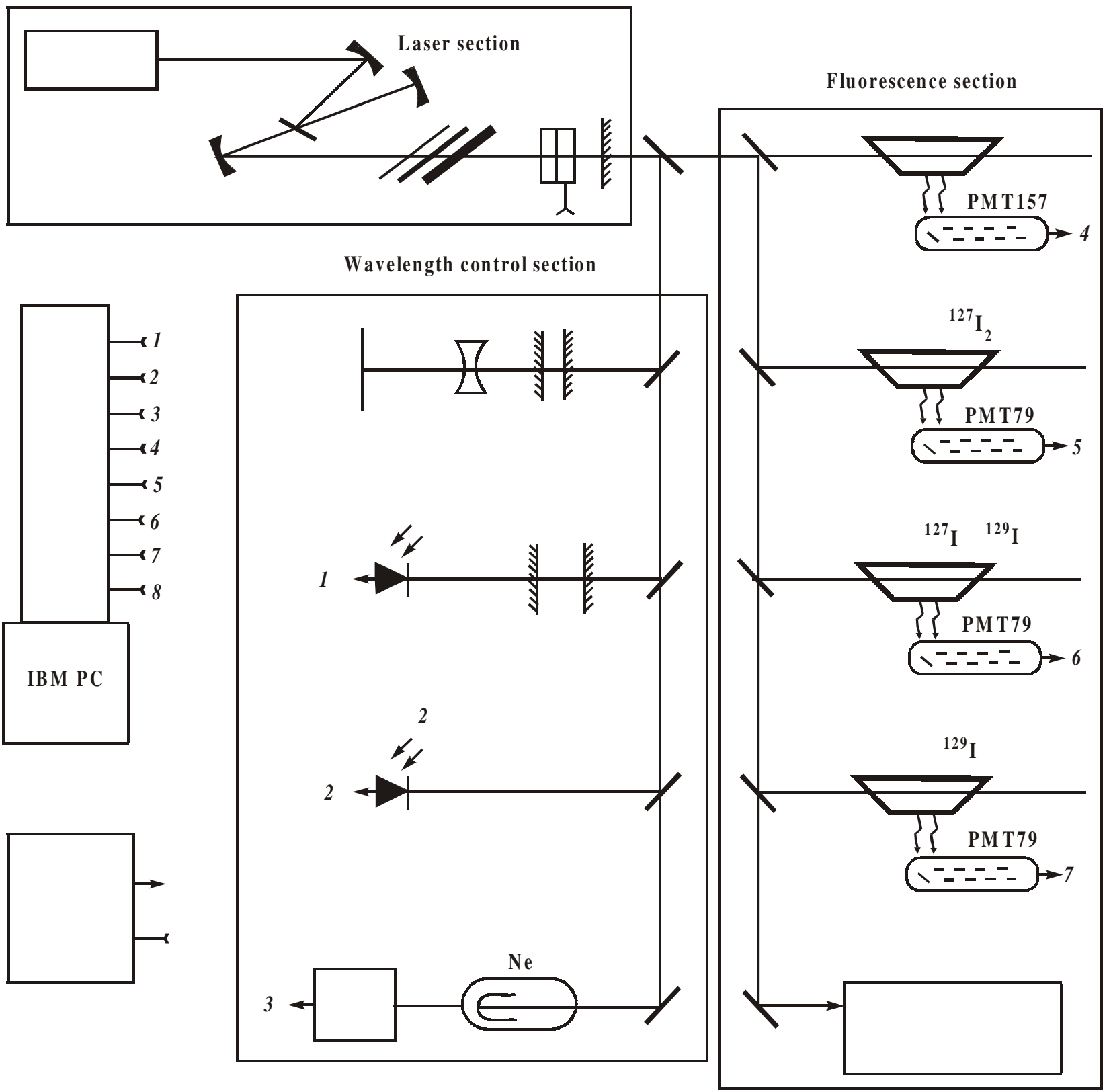

Fig. 12. The experimental setup for laser fluorescence test of iodine cells.

\section{References}

1. T.J. Quinn, Practical realization of the definition of the metre // Metrologia, 36, pp. 211-244 (1999).

2. H.R. Simonsen, Iodine-stabilized extended cavity diode lasers at $\lambda=633 \mathrm{~nm} / /$ Proc. SPEM-96, p. 94 (1996).

3. J.-M Chartier, J. Helmcke, A.J. Wallard, International intercomparision of the wavelength of iodine-stabilized lasers // IEEE Trans. Instrum. Meas., IM-25, pp. 450-453 (1976).

4. J.L. Hall, C.J. Borde, Shift and broadening of saturated absorption resonances due to curvature of the laser wave fronts // Appl. Phys. Lett., 29, pp. 788-790 (1976).

5. P. Cerez, R. Felder, Gas lens effect and cavity design of some frequency stabilized He-Ne lasers // Appl. Opt., 22(8), pp. 1251-1256 (1983).
6. A.V.Mironov, V.E. Privalov, Frequency shifts in $\mathrm{He}-\mathrm{Ne}^{127} \mathrm{I}_{2}$ lasers // Elektronnaya tekhnika, lasernaya tekhnika $i$ optoelectronica, 1(57), pp. 51-58 (1991), (in Russian).

7. M.V. Danileyko, A.L. Kravchuk, A.M. Teslinko, L.P. Yatsenko, Asymmetry of non-linear resonances and frequency shifts in stabilizad $\mathrm{He}-\mathrm{Ne} /{ }^{127} \mathrm{I}_{2}$ lasers // Kvantovaya elektronika, 13(3), pp. 516-522 (1986), (in Russian).

8. A.V. Boyko, A.M. Negriyko, L.P. Yatsenko, Iodine stabilized He-Ne laser pumped by a transverse rf-discharge // Semiconductor Phys., Quantum El. and Optoelectronics, 2(1), pp. 133-141 (1999).

9. F. Spieweck, Influence of small impurities in absorption cells of $\mathrm{I}_{2}$ stabilized lasers upon their frequency lasers // IEEE Trans. Instrum. Meas. IM-34, pp. 246-248 (1985). 


\section{A.M. Negriyko et al.: Design and testing of iodine cells for ...}

10. G. Flory, M. Broyer, J. Vigue, J.C. Lehmann, Perturbation de l'iode moleculaire en phase vapeur par la presence de gaz entrangers consequence pour la stabilisation du laser He-Ne // Rev. de Phys. Appliquee, 12, pp. 901-904 (1977).

11. S. Picard-Fredin, A study of contamination in ${ }^{127} \mathrm{I}_{2}$ cells using laser-induced fluorescence // Metrologia, 26, pp. 235244 (1989).

12. J.-M. Chartier, S. Picard-Fredin, A. Chartier, International comparison of iodine cells // Metrologia, 29, pp. 361-367 (1992).

13. P. Gill, R.C. Thompson, The preparation and analysis of iodine cells // Metrologia, 23, pp. 161-166 (1986/1987).

14. E. Howick, N. Brown, J.-M. Chartier, International comparison of iodine cells for laser length standards // Metrologia; 33, pp. 173-175 (1996).

15. G.H. Popescu, M. Necsoiu, J.-M. Chartier, S. Picard, A. Chartier. A study on the spectral characteristics of the iodine cells from IFA-IFTAR used in $\mathrm{He}-\mathrm{Ne} /{ }^{127} \mathrm{I}_{2}$ lasers // Romanian Journal of Physics, 40, pp. 491-495 (1995).

16. J. Hu, E. Ikonen, K. Riski, Frequency Shift of Iodine Absorption Components Caused by a Small Amount of ${ }^{127} \mathrm{I}^{129} \mathrm{I} / /$ Metrologia, 31, pp. 389-394 (1995).

17. O.V. Boyko, N.M. Kachalova, A.M. Negriyko, L.P. Yatsenko, Yu.P. Machekin, V.M. Smulakhovsky, Collation of He-Ne/ ${ }^{127} \mathrm{I}_{2}$ lasers of the State length unit etalon of Ukraine // Ukrainskii metrologichnyi zhurnal, 1, pp. 47-49 (1999) (in Ukraine).
18. O.V. Boyko, A.M. Negriyko, L.P. Yatsenko, Asymetry of safurated absorption resonance in $\mathrm{He}-\mathrm{Ne} /{ }^{127} \mathrm{I}_{2}$ lasers with excitation by RF discharge // Kvantovaya elektronika, 29(8), pp. 516-522 (1999), (in Russian).

19. P. Cerez, A. Brillet, Factors which limit the reproducibility of iodine stabilized He-Ne lasers // Metrologia 13(1), pp. 2933 (1977)

20. F.Bayer-Helms, J.-M.Chartier, J.Helmcke, A.J.Wallard, Evaluation of the International intercomparison measurements (March 1976) with ${ }^{127} \mathrm{I}_{2}$-stabilized He-Ne lasers. Spacing of the hyperfine structure components // PTB-Berict PTB-ME17, pp. 139-146 (1977)

21. A.M. Negriyko, O.V. Boyko, N.M. Kachalova, V.M. Khodakovskiy, Laser fluorescence tests of iodine vapor cells // SPIE Proceed., v. 5137, pp. 393-400 (2002).

22. M.V. Danileyko, A.M. Negriyko, V.I. Romanenko, V.M. Khodakovskiy, L.P. Yatsenko, Laser-fluorescent spectroscopy of heteroisotopic molecular iodine // Optika i spektroskopiya, 79(1), pp. 77-84 (1995), (in Russian).

23. V.I. Balykin, V.I. Mishin, V.A. Semchishin, Detection of low I 2 vapor concentration using the method of laser-exited fluorescent // Kvantovaya elektronika, 4(7), pp. 1556-1558 (1977), (in Russian). 